\title{
Maultsby's Rational Behavior Therapy: Background, Description, Practical Applications, and Recent Developments
}

\author{
Mariusz Wirga ${ }^{1,2}$ (D) Michael DeBernardi ${ }^{3,4,5} \cdot$ Aleksandra Wirga $^{2}$. \\ Marta L. Wirga ${ }^{2}$. Marta Banout ${ }^{6}$. Olga Gulyayeva Fuller ${ }^{7}$
}

Published online: 24 February 2020

(c) The Author(s) 2020

\begin{abstract}
In this article we present Maultsby's Rational Behavior Therapy (RBT) as a unique and distinct, but underutilized form of cognitive-behavior therapy, including its origins, theory (with psychosomatic learning theory), basic concepts, and practical applications, as well as never before published recent developments. As readers will see, many of Maultsby's concepts, while pioneering and beckoning the third wave, still remain fresh, validated by current cognitive neuroscience, and are very relevant to modern psychotherapeutic practice. We describe RBT's valuable concepts and effective techniques in such a way that readers may readily start using them to complement and enhance any other form of cognitive behavior therapy. An article comparing RBT with REBT and CBT will follow.
\end{abstract}

Keywords Rational Behavior Therapy · Psychosomatic Learning Theory · ABCD model of Emotions · Five Rules for Healthy Thinking · Cognitive-emotive dissonance $\cdot$ Emotional re-learning

Marta Banout

martabanout@gmail.com

Mariusz Wirga

mwirga@NowIsOK.com

1 Psychosocial Oncology, MemorialCare Todd Cancer Institute, Long Beach Memorial Medical Center, Long Beach, CA, USA

2 Wellness Psychiatry, Inc, Long Beach, CA, USA

3 The Life Link - Community Mental Health Center, Santa Fe, NM, USA

4 DeBernardi Psychological Services, Inc, Santa Fe, NM, USA

5 University of New Mexico Continuing Education Substance Abuse Studies Program, Albuquerque, NM, USA

6 Institute of Psychology, University of Silesia, Katowice, Poland

7 St. John's University, Queens, NY, USA 


\section{Introduction}

Maxie Clarence Maultsby, Jr., MD (1932-2016), was an internationally known black $^{1}$ psychiatrist who achieved his acclaim primarily as an early contributor to the development of cognitive-behavioral therapies and the founder of Rational Behavior Therapy. In this article, the authors describe the unique characteristics of RBT and Maultsby's contributions to the field of cognitive-behavior therapies. This is particularly important because in the time since the publication of his seminal RBT manual (Maultsby Jr 1984) most of the new developments in RBT have come about via oral transmission in training workshops, lectures conducted by Maultsby himself, Marta Banout, Alina Choteborska, Michael DeBernardi, Aurelia Dembińska, Tomasz Dróżdż, Wojciech Falkowski, Agnieszka Hottowy, Agnieszka Kałwa, Iwona Nawara, Maciej Skibinski, Aleksandra Wirga, Mariusz Wirga, and Ewa Wojtyna, and have not been published outside the training workbooks, course materials and handouts, and informal communications. Also, the above mentioned are the people contained in the collective "we" for the remainder of the article (while ultimately referring to the authors' opinions), though it could also refer to the common human experience. The most current version of the RBT model is that presented in the Polish edition of the RBT book (Maultsby Jr 2013) and the upcoming edition expanded to two volumes of "ABC of Your Emotions" (Maultsby Jr et al. 2020). The aim of this paper is to present an overview of Maultsby's RBT model. A separate article will follow highlighting similarities and differences from more well-known CBT models including Albert Ellis' Rational Emotive Behavior Therapy (REBT), and Aaron Beck's Cognitive Therapy (CT).

To help the reader get a feel for RBT in action, and to distinguish it from REBT and CT, this article will present RBT in the same manner in which it is presented to the therapy participant, building one concept upon another as they are understood and mastered. Thanks to its unique qualities that Maultsby considered the characteristics of an ideal psychotherapy-comprehensive, short-term (yet giving long-term results), culture-free, non-pharmacological (yet compatible with the use of psychotropic medications), applicable as therapeutic and preventative, as well as a way of self-development-RBT became a very useful part of the armamentarium of any psychotherapist and to this day remains compatible with all therapies based on the learning theory of human behavior (Maultsby Jr 1984). Perhaps most importantly, RBT was the first of the cognitive-behavior therapies that was developed specifically to be used as a self-counseling technique (Maultsby Jr and Winkler 1972).

Dr. Maultsby often pointed to his years in practice as a family physician that sparked his interest in finding ways to effectively address the emotional disturbances that he saw as the root of most of his patients' physical complaints. In his book, Rational Behavior Therapy (Maultsby Jr 1984), he credited the 15 years of study of these nine scientific approaches as the foundation of his therapy:

${ }^{1}$ Dr. Maultsby preferred being called "Black" rather than "African-American". 
1. The art and science of practicing family medicine.

2. Specialty training in adult and child psychiatry.

3. Neuropsychological theories of Donald Hebb and Alexander Luria.

4. Classical conditioning theory of Ivan Pavlov.

5. The operant learning theory of James G. Holland and B. F. Skinner.

6. Learning theories of Hobart Mowrer and Julian Rotter.

7. Conditioning and learning research of Clarence V. Hudgins, Mary Cover Jones, John I. Lacey, and Robert L. Smith, Charles E. Osgood and George J. Suci, Gregory H. S. Razran, Arthur W. Staats and Carolyn K. Staats, John B. Watson and Rosalie Rayner, Joseph Wolpe, and Arnold Lazarus.

8. Psychosomatic research of David T. Graham and William J. Grace.

9. Albert Ellis's theory and technique of Rational Emotive Therapy.

\section{ABCD Model of Emotions}

Ellis formulated the ABC model of emotions, and, as Dryden wrote, "Ellis has always been clear that beliefs do not cause disturbed or constructive responses to adversity. To make this claim would be tantamount to saying that beliefs are completely separate from feelings, a stance that would violate the principle of psychological interdependence that has been present in REBT theory since its inception" (Dryden 2012b).

While adopting Ellis' ABC model of emotions, based on his study of neuropsychophysiology Maultsby assumed the most radical position that "with their cognitions (B-thoughts, beliefs, and attitudes) humans create, maintain, and eliminate all their emotional feelings (C)" which in turn are the motivating force for physical actions (D). ${ }^{2}$ He considered all components of ABC (perceptive, cognitive and emotive) as a "whole emotion" with "C" being only the feeling part (emotive) of the emotional experience that was "always the logical consequence of the cognitive part (B)." Maultsby often said that, as a physician, he was more interested in basing his approach on brain physiology than on philosophy. He is not alone in this radical position of cognitive causation of emotional feelings, as already in 1980 it was strongly expressed by Burns, "your emotions result entirely from the way you look at things" (Burns 1981). Burns also pointed out that many CBT therapists, unfortunately, do not fully embrace this neurobiological fact (Burns 2005, 2017). This view is consistent with the recently proposed by Daniel David general model Integrative and Multimodal CBT/IM-CBT (David and Cristea 2018).

A. Activating event: (sensory perceptions of a stimulus, what you perceived happening)

B. Cognitions: Your sincere thoughts, Beliefs, and attitudes about that activating event

\footnotetext{
2 Originally Maultsby used $\mathrm{ABC}_{1} \mathrm{C}_{2}$ model of emotions in which $\mathrm{C}_{1}$ were emotional feelings and $\mathrm{C}_{2}$ were physical actions. In early $2000 \mathrm{~s} \mathrm{C}_{2}$ was renamed to D (mnemonic for "doing").
} 
C. Emotional feelings: The emotional feelings that you experience as the Consequence of your thoughts, beliefs, and attitudes

D. Physical behaviors ${ }^{3}$ : The action(s) that you take as a result of the event. (What you Do.)

We have three basic emotive choices depending on how we evaluate any given situation:

1. If we believe a situation is a threat to our survival, comfort, or self-control, we experience negative emotional feelings that motivate us to a flight or fight response.

2. If we believe the situation is beneficial to our survival, comfort, or self-control, we experience positive emotional feelings that motivate us to stay or go after the source.

3. Finally, when we determine that a situation is neutral (indifferent) to our survival, etc., we experience neutral emotions that motivate us to stay in the current situation or allow us to motivate ourselves to pursue our goals independent of the current situation (Wirga and DeBernardi 2002).

It is important to note that what Maultsby considered to be an emotional feeling (C) was the hard-wired physiological response to the evaluative process in $\mathrm{B}$. For example, in the case of fear we have the well-established amygdala-mediated fear cascade starting with the startle response, freezing, and then bradycardia (parasympathetic nervous system), followed by increase in blood pressure, tachycardia, goosebumps, pupil dilation, pallor, cold sweats (mediated by the sympathetic nervous system) as well as the neuroendocrine responses (related to the release of "stress" hormones by the pituitary and adrenal glands). In this fear cascade, both startle and freezing seem to be responses shared by all mammals to a threat. However, only the startle response (that can be elicited by any sudden strong stimulus) seems not to be mediated by the evaluative process (B) in the neocortex because it is receiving the direct but crude input from the sensory thalamus and amygdala via reticulopontis caudalis and therefore refractory to extinction but it is the cortical input that determines the rest of the cascade. Most of us have experienced being startled by a sudden stimulus but once we notice that the source of it is benign (e.g., our own child trying to "spook" us), the fear cascade is interrupted by the neutralfor-survival meaning (B) ascribed by the neocortex. On the other hand, when the stimulus is confirmed by the neocortex to have a negative-for-survival meaning (B), the rest of the fear response will be experienced (LeDoux 2002; Wirga and DeBernardi 2002).

\footnotetext{
${ }^{3}$ Maultsby, similarly as Skinner and others, considered thinking as behavior too, therefore he was very specific that $\mathrm{D}$ was describing overt, physical behaviors. However, in the rest of this article, the term "behaviors" will refer to physical behaviors, and for covert cognitive behaviors we will use the term "cognitions".
} 
Ellis theorized, and Maultsby agreed, that any of the A, B, C, and D components could become a new activating event, A. This concept was expanded in 2002 by Wirga and DeBernardi (in advanced RBT workshops "From Chaos to Self-Organization") - that each component could affect any other component of ABCD and the expanded the ABCD model as shown in "Appendix 1". A belief or a thought in B can become an activating event (A) for a new evaluative thought and a whole cascade of other (often habitual) negative associations. If we are convinced about something, our brain habitually pays attention to the things that confirm our beliefs (Rahnev et al. 2011; Rahnev et al. 2016). We are in agreement with the recent developments in cognitive neuroscience that the hard-wired physiological reactions become the substrate of higher order processing of emotional consciousness (LeDoux and Brown 2017; LeDoux and Hofmann 2018; Schachter and Singer 1962). The emotional feelings (C) can become the new activating event (A) in ABCD and therefore people can experience secondary depressions or anxieties described early on by Ellis.

We also agree that our emotional feelings may affect how we think about what is happening around us, as Ellis astutely pointed out, when we experience prolonged fear and arrive at conclusions that there is actually nothing to be afraid of (Ellis 1979). Moreover, the actions (D) may become an activating event (A) or change it. For example, by engaging in a new activity and succeeding in it, a person can arrive at the conclusion that actually it is not as difficult as it seemed. This may increase their belief (B) in their capacity to do it. Our actions influence how we think about ourselves and our capacity to act. Self-efficacy is a significant element in the process of change - the more consequently we engage in new behaviors, the more convinced we can become that they are not impossible at all, that they are not that difficult, or that they are even easy once you get to them. Furthermore, when a person retreats from the situation in which they habitually get angry, then further exposure to the perception of this stimulus (A) is prevented and leads to a decrease in negative thoughts and emotional feelings. An event that is not perceived is not going to elicit any response. Engaging in a new behavior may also serve as a powerful distraction, almost forcing the change in thoughts and consequently emotional feelings.

The above observations do not negate Maultsby's basic assertion that emotional feelings (C) are a logical consequence of sincere thoughts, beliefs and attitudes (B) about perceived activating events (A). In 1995, the strongest endorsement from cognitive neuroscience research came from the statement by LeDoux that emotional learning is not response learning but stimulus learning. This means that we do not learn how to emotionally react to a perception of a certain stimulus (A), but our emotional feelings $(\mathrm{C})$ are the consequences of the meaning we give in $\mathrm{B}$ with the appraisal by our beliefs, thoughts and attitudes of the perceived stimulus (A) (LeDoux 1995).

The first therapy session in RBT is dedicated to the presentation and integration of the ABCD model of emotions. No new concepts of RBT are introduced until 
therapy participants ${ }^{4}$ not only understand its basic premise but also accept it and are able to demonstrate how it applies to their lives. It may take several sessions, but once done then the participant is introduced to the Five Rules for Healthy Thinking.

\section{Five Rules for Healthy Thinking (5RHT)}

Since, in Maultsby's estimation, it was unhealthy thinking that caused an emotional disturbance, he focused on formulating clear-cut objective criteria that would help his patients recognize it. He also wanted his patients to practice healthy thinking between their therapy sessions that would lead to the optimal emotional health, but none of the definitions of "rational" made useful sense to him (Maultsby 1984, pp. 13-14). In 1970, he arrived at the very practical definition of rational and therefore healthy thinking as following these rules-The Five Rules for Healthy Thinking $(5 \mathrm{RHT})^{5}$ :

1. Healthy Thinking is based on obvious facts (objective reality);

2. Healthy Thinking best protects my life and health;

3. Healthy Thinking best helps me to achieve my short and long-term goals;

4. Healthy Thinking best helps me to prevent or handle ${ }^{6}$ the most unwanted conflicts with others;

5. Healthy Thinking best helps me feel the way I want to feel, without abusing any substances.

Moreover, regarding healthy thoughts and beliefs:

- A healthy belief obeys at least three of the five rules.

- What is healthy thinking for me does not have to be healthy for another person, so what is healthy for the therapist does not have to be healthy for the participant.

- What is healthy for me today does not have to be healthy for me at other times.

- All the rules are equally important.

- Some rules may not be applicable in certain situations (e.g., rule number one doesn’t apply to religious, spiritual, philosophical or existential beliefs).

Unlike other approaches in which the therapist was the arbiter of what beliefs were rational or not, these rules made it very easy for people to assess their own thinking and formulate what was healthy for them to think without the need for input from a therapist or learning to identify patterns of cognitive distortions (that,

\footnotetext{
${ }^{4}$ Since RBT is often used in non-clinical populations we often use the term "participants" instead of "patients" or "clients".

${ }^{5}$ Initially these were known as Rules for Rational Behavior then Rational Thinking and eventually Healthy Thinking.

${ }^{6}$ Previous version of 4th RHT had "avoid or resolve" instead of "prevent or handle" which was the last change Maultsby made to the 5RHT in 2014.
} 
in 1970 , were yet to be defined). Rational thinking, as formulated by the participant is healthy thinking and leads to rational and healthy emotions and behaviors. This laid ground for Rational Self-Counseling, as from the ABCD and 5RHT derive all other concepts and techniques of RBT that can be applied by people who want to improve their emotional functioning.

\section{Healthy Semantics}

Once participants learn to apply ABCD and 5RHT to themselves, they are presented with Healthy Semantics, which is most often given in the form of a written handout. Ellis adopted the concept of Healthy Semantics from Korzybski's General Semantics (Korzybski 1935), and Maultsby expanded on the concept by applying the first RHT (the healthy thought is based on facts). It addresses many common words and phrases to which we are conditioned to respond with negative emotions, consistent with Pavlov's observation that "for people, the word is an entirely real stimulus; and it signals and substitutes for every other stimulus and induces every kind of reaction other stimuli induce" (Maultsby Jr 1984).

These words and/or phrases include such absolutistic or dichotomous statements as: always, never, everything, nothing, everybody or nobody, I have to, I need to, I must, I should, I ought to, It's not fair, etc. It is in step with Ellis' observations about the role of absolutistic thinking, with a greater focus on it (Ellis 1987). Maultsby did not call for a dogmatic ban of these words but suggested we be mindful of their use, recognize their role in emotional disturbance, and avoid them if they are causing it. Replacing a negatively associated word with a neutral one may be a minor semantic change that may have significant emotional benefit. His observations are consistent not only with early insights of Pavlov, but with recent research linking semantics to anxiety, depression, suicidality, eating disorders, and borderline personality disorder (Al-Mosaiwi and Johnstone 2018). Also, recent research shows a neurobiological basis for the earlier observations (Pulvermüller 2013; Tomasello et al. 2017). Recognizing these words and understanding how they influence cognitions and emotions will help the participant learn to master the next technique, Rational Self-Analysis.

\section{Rational Self-analysis (RSA)}

RSA is a structured self-help technique, routinely given as a homework assignment for participants to complete every time they experience a significant emotional disturbance (Maultsby Jr 1971b). It helps them discover causal relationships between the cognitive, emotive, and physical components of their behavioral problems. Participants are asked to divide a page in half and to put the problem they encountered in the format of the ABCD model of emotions in the left column (see the Standard RSA Form below). The right column serves to check the accuracy of the perceptions of the event (HA), formulating a healthy belief that would obey at least 3 of the 5 RHT in HB, as well as formulate healthy emotive (HC) and physical behavioral (HD) goals. 
Many CBT approaches give patients some form of written homework to record their cognitions, emotions and physical behaviors. The unique feature of RSA is its emphasis on self-help and the fact that it involves a check of accuracy of perceptions with its Camera Test (HA). It also makes evident that inferences, which in Ellis' REBT are part of A (Dryden 2012a), would not pass this test and would belong to the $\mathrm{B}$ section in RBT. Also, the form is used in group RBT (gRBT) and requires the participant to just complete the left column of the form prior to the session and get help from the group to complete the right column ("Appendix 2").

Once an RSA is complete, the participant is asked to assure that the right column is free of any unhealthy semantics statements, that each of the healthy belief in section HB obeys at least three of the 5RHT, and that the emotive and behavioral goals in $\mathrm{HC}$ and $\mathrm{HD}$ will be the logical consequence of the perceptions and cognitions in sections HA and HB. The particular value of this written exercise is that the same form that records the disturbed perceptions, cognitions, emotions and physical behaviors serves as a way to challenge them and formulate their healthy counters and serves as the basis of the future emotive-behavioral practice, Rational Emotive Imagery.

\section{Rational Emotive Imagery (REI)}

The emotional and behavioral problems that RBT addresses are learned habits. We, as humans, cannot just get rid of a habit even with the strongest effort of will. We can only replace it by practicing a new and hopefully healthier habit. As will be further elucidated in the next section on learning theory, the process of learning a new, healthy, and lasting emotive and behavioral response to an old situation involves replacing an old habit with a new one. Maultsby wrote, that "an essential part of learning a habit is a constant, split-second-to-split-second, brain-body feedback" (Maultsby 1984, p. 195). Unfortunately, the majority of practitioners do not realize this, so even if they assign behavioral practice, it is often not practiced frequently or systematically enough to replace the old habits. Even if they did, life still does not offer us enough opportunities to practice in vivo. When opportunities do arise, they come when we are least prepared and we end up habitually acting in an old way. This is indeed unfortunate because in order to replace a habit we need to practice it more often than the old habit and sustain this practice relatively consistently for a period of time.

Rational Emotive Imagery (REI) is a form of intense mental practice for learning new emotional and physical habits that allows people to rehearse "thinking, emotive feeling, and physically behaving exactly the way they want to think, feel and act in real life (Maultsby Jr 1971a, 1984). To practice REI, the participants are asked to memorize the right (healthy) side of their RSA, keep it handy, and schedule undisturbed time for practice of about five to ten minutes, four or more times per day. To make it easier, at the end of the session the RBT therapist often audio-records an REI script on the participants' smartphone, so they can listen to it as mental practice. At the scheduled time, they are asked to assume a comfortable position (lying down, sitting, or standing) and put themselves in a state of relaxation with what Maultsby 
called the Instant Better Feeling Maneuver (involving slow, mindful, diaphragmatic breathing with a soft smile on the face). Once a participant is relaxed, they are asked to imagine or think about themselves back in the situation HA, but this time feeling emotionally and behaving physically as described in their goals in sections $\mathrm{HC}$ and HD and thinking as described in section HB. Participants are also encouraged to do brief REIs in less formal ways whenever they have time, such as when on hold while on a phone call, standing in line, and in any other similar situation.

During this imagery rehearsal of new, healthy thoughts, participants are advised to keep each healthy thought in their minds for about half a minute (which is four to eight mindful breaths depending on the rhythm of their breathing) while maintaining the calm breathing and soft smile on their faces which allows for them to get "an emotive hold of a new healthy thought" before proceeding to the next thought. Participants are encouraged to expand their REIs to events that are logical to their healthy thoughts in $\mathrm{HB}$ as well as their HC and HD goals. It is not recommended, however, to do REI on more than two unrelated RSAs in one ten-minute session.

So, is the mental practice in REI actually working to replace the old habit with a new one in real life? It turns out we cannot learn a new behavior if we cannot imagine ourselves doing it. To successfully perform a new skill, we need to be continuously telling ourselves the instructions for this new behavior, which is a form of imagery. Eventually, this practice will become second nature, and once the new habit is established, the most reliable evidence of habit formation is that it will come with minimal conscious thoughts (Maultsby Jr 1984, p. 195).

The underlying learning theory and its implications for practice need to be explained before REI is assigned so that participants know why imagining the new healthy thinking, emoting and behaving (in a way that is in conflict with old unhealthy habits) often feels wrong, weird, awkward and unnatural at first, even when it is the right and healthy thing to do.

\section{Psychosomatic Learning Theory and Why What Feels Wrong May Be the Right Thing}

RBT like other cognitive therapies focuses on the present moment issues and considers that our past affects our present only through memories and habits, both of which we can change (through learning how to recall the past in healthy ways and forming new habits by practicing new healthy Bs, Cs, and Ds). It also shares with REBT that "you don't have to understand where the problems came from to actively work to change them in the present. Clients can waste years trying to pinpoint the event or moment in time when their disturbance began without making any positive changes in the present" (MacLaren et al. 2016). However, Maultsby was keenly interested in the psychobiological underpinnings of a cognitive, emotive, and behavioral change, therefore both theory and practice of RBT utilize the following neurobiologically rooted theory of the process of such a change.

This process, as explained by the Psychosomatic Learning Theory (also often called Rational Cognitive-Behavioral Learning Theory), is one of Maultsby's most unique and important contributions. It is consistent with cognitive 
neuroscience research that emotional learning is not learning a new way of reacting to a perceived stimulus, but rather learning of the new meaning of this stimulus (LeDoux 1995) and making this new meaning a new attitude. A detailed description and supporting research is presented elsewhere (Maultsby Jr 1984, pp. 50-68, 163-172). Here we summarize these concepts while maintaining the original terminology.

After Pavlov, Maultsby considered language to be the primary component in one's personal sense of conscious reality because the left-brain language system (left for most people) converts perceptions into linguistic representations of reality, monitors them continuously, and labels and organizes these perceptions as cognitive, emotive, and physical behaviors.

Learning any new habit, emotional or physical, follows the same stages and is analogous to learning to drive. Also, it follows the ABCDs of emotions:

\section{A Perceptions related to driving, visual, kinesthetic, etc. \\ B Correct self-instructions \\ C Logical emotive response to B \\ D Logical and appropriate driving physical action for B}

First, one must learn to correctly use the pedals, steering wheel, gearshift, turn signals, rear-view mirrors, etc. in a specific way, as well as understanding the traffic rules. This is "intellectual insight" (the first stage in emotional learning), or knowing what must be practiced to learn the desired behavioral habit. Still, attending the best lectures or even memorizing the best books on the subject is not sufficient to acquire the new skill of driving. Practice (both mental and physical) is necessary and is the second stage in emotional learning, which involves perceiving, labeling, processing through self-talk, and mental images or correct physical driving to trigger the desired mental and physical responses and emotive reactions. When learning to drive, the mild "right" feelings reinforce the correct self-talk, appropriate mental images or cognitive maps and correct actions. This makes incorrect driving thoughts, mental images, and actions feel wrong which constitutes the third stage of learning-Emotional Insight.

The fourth stage of emotional learning is "new habit formation." This happens when one has practiced a habit to the point that it becomes his or her predictable behavioral characteristics. This is reached by consistently acting out correct driving Bs, Cs and Ds to traffic situations (e.g., adjusting the speed to the traffic around, looking in the rearview mirrors, appropriate use of turn signals, stopping at the red light, etc.). The well-established habitual behavior becomes automatic and does not require any conscious thoughts at this point.

Unlike with conscious and intentional learning of a driving habit, people acquire most of their emotional habits unwittingly, and often without any physical practice. For example, most people learn their fear of flying on commercial airplanes (flying phobia) only through mental practice. As we established earlier, habits form when perceiving the similar stimulus (A), while having the same type of thoughts (B) that trigger the same emotional feelings (C) and same actions 
(D). This happens when a person hears about an airplane crash on the radio (A) and thinks at $\mathrm{B}$ of how dangerous it is being on the airplane, ${ }^{7}$ how terrible and scary it would be if she were on the plane, etc., and as a consequence experiences emotional feeling of fear and anxiety $(C)$. She may unintentionally rehearse these negative associations of planes, negative thoughts, and fear frequently enough to establish a new habit of fear of flying.

According to the ABCD model, the above described hard-wired subcortical emotional processing system responds to perceptions and thoughts with either a positive, negative, or neutral emotive urge for action, which is how humans know when to protect themselves. When the brain thinks the same thoughts about the same perceptions and gets the same emotive and behavioral responses then the left brain pairs the perceptions and thoughts into semi-permanent beliefs. After beliefs are formed, the left brain no longer needs to process stimuli as single mental events. Instead, the left brain's words elicit beliefs (a-B apperceptive units) that trigger the right brain's habitual emotional and physical reactions. Using the fear of flying example, at this stage, a person would not need to see an airplane, but only have the belief that the next airplane flight would certainly end in a crash to trigger the emotion of fear. Yet, people rarely see these kinds of emotional reactions as an "emotional practice," which occurs every time they repeat any specific emotional reaction in a specific situation ("Appendix 3").

As left brains form beliefs, right brains form attitudes. Attitudes are wordless, and beliefs are the spoken or conscious form of attitudes. Attitudes code every habitual thought, cognitive map, or mental image we perceive. For this reason, people can react with instant, automatic, seemingly involuntary, emotional and physical reactions to old perceptions and events. This is the stage of "emotional insight," which means having the most logical emotive response at $\mathrm{C}$ for the paired A-perceptions and B-thoughts. This involves tying A, B, C \& D into a behavioral gestalt that is an "emotive rope" or "emotive glue" (described as "feeling right"). These attitudes create the illusion that external HEs, SHEs, ITs, and THEYs control one's emotions. With emotional insight in driving, one may have an impression that a pedestrian suddenly appearing in front of your car in A is "causing" you to correctly press the breaks and swerve out of the way, without thinking anything in B, while in fact, these were habitual attitudes of which you were not conscious. The correct-driving movements "feel right." However, when a mistake is made (like shifting into a wrong gear) one knows that it is not some external IT that made the mistake but one's own hand. Similarly, it is one's own A-b attitudes that trigger an emotional or physical response at $\mathrm{C}$ and $\mathrm{D}$, not the pedestrian.

Since most of our emotional habits are learned without any conscious effort, attitudes are silent, and habitual emotional responses seem automatic non-verbal reactions to Activating Events, how can one uncover the content of these attitudes and check if they are healthy or not? Actually, in an emotional crisis situation, the wordless attitudes are actively thought and therefore, converted into verbal beliefs. That is why RBT therapists believe that such a crisis is an excellent opportunity

\footnotetext{
7 Despite the evidence to the contrary, that commercial airplanes are the safest way to travel.
} 
for self-discovery and strongly urge people in these situations to write down what is on their minds. This is also possible to recreate in a therapy session but not as easy because people resist feeling emotional pain and, without an Activating Event A, are reluctant to recreate the attitudes that caused them. Once these beliefs are written down in the form of RSA, REI is practiced. This is the way of changing the beliefs and attitudes through the process of emotional re-learning. To see how this process is different from emotional learning, we return to the driving example ("Appendix 4").

Once the driving habits and attitudes are well established, emotional re-learning is analogous to re-learning to drive in a country with opposite-hand side traffic, such as Americans re-learning driving in left-hand side traffic in the United Kingdom. It also follows the same ABCDs sequence of learning but as soon the person thinks of driving in the left-hand side traffic it immediately feels wrong. This is an experience of the inevitable stage of emotional re-learning called cognitive-emotive dissonance when people have new thoughts (and possibly actions) that are in conflict with the habitual emotional feelings in a familiar situation. People experience this as if the new thoughts and behaviors feel "wrong," "weird," "awkward," or "unnatural." Patients (and most therapists for that matter) usually do not understand this phenomenon and, unfortunately, this is the point when most people abandon their efforts at learning and implementing any change because nobody likes to do what feels wrong when they can instead revert to habitual "gut thinking" that feels right and comfortable. To prevent this natural resistance to change, participants in RBT are educated about it before they experience it, even before their first RSA, so they will be prepared that new healthy thoughts will often feel wrong to them and what that really means.

To teach the process of emotional re-learning we routinely use this driving example, in which American participants are asked to imagine themselves driving for the first time in the United Kingdom. They are instructed that the traffic there is lefthand side, which is the Intellectual Insight stage. Then we ask them to imagine the driving differences, that the steering wheel is on the right side of the car, that the gears are shifted with the left hand, and that in order to join the traffic they need to check the right rear-view mirror for traffic. This is the second stage of emotional relearning of Practice. Just imagining it feels wrong, and even participants who do not drive can easily relate that actually doing it would feel very wrong, which immediately would put them in the third stage of emotional re-learning, Cognitive-Emotive Dissonance. Just as this is a learned habit ("gut feeling") that is difficult to change instantly, so are emotions. The increased cognitive cost of reappraisal in habitual responses is recognized in modern research but unfortunately does not address cognitive-emotive dissonance (Ortner et al. 2016).

If American drivers drove the American way in the United Kingdom they may "feel right," but this would clearly be wrong and dangerous. That means that the feeling wrong does not mean that the thought or act is wrong, but that it is only in conflict with our habits that feel right. Also, even if they drove that first day successfully in the United Kingdom, ignoring gut feelings and thinking rational thoughts, this would not mean that the American driving habits have been changed. In the same way, participants cannot expect instant emotional 
change but need to practice until new habits are formed. Also, even though the British driving may feel unnatural, actually it does not mean it is against their nature, and it does not mean that it will always feel that way.

In order to safely drive in the UK, American drivers need to consciously follow their new left-hand side driving self-instructions despite them feeling wrong and ignore the impulses to drive according to their old right-hand side habitual driving attitudes despite them feeling right. This self-instruction, or new selftalk, is the necessary mental part of practicing a new habit. It makes sense that one cannot practice a new way of behaving in an old situation without first imagining it and that the physical practice in real life includes conscious mental practice too. Also, they will acquire new driving habits sooner if they take time to practice it in imagination (REI) and not limit themselves to the practice opportunities they have to drive in real life.

According to Maultsby, during cognitive-emotive dissonance, the left brain entertains new verbal thoughts that are different from the right brain's habitual, attitude-triggered, non-verbal responses. Normally left brains react to this feeling by rejecting new ideas. It is important to remember that believing an idea makes it "true" for the believer, which is why people do not accept an idea they believe is incorrect (even if that idea may be an objective, verifiable fact!). Participants benefit most from thinking new ideas when they give themselves meaningful reasons to think them (for example, being able to verify them with 5RHT). A new healthy idea never works by itself, however. Instead, people need to work on it and follow these three simple steps in eliminating emotional habits: recognizing unhealthy beliefs and attitudes that support the undesirable habits (5RHT), replacing these unhealthy beliefs and attitudes with new healthy thoughts one is willing to accept (RSA), and practicing acting out new ideas until they become beliefs and attitudes to create a new habit (REI).

With practice, American drivers will eventually develop a "feel" for driving in the left-hand side traffic, in other words, gain Emotional Insight, which is the fourth stage of emotional re-learning. With further practice the new British driving will come as naturally and feel as right as the old American driving did before and reach the final stage of emotional re-learning, New Habit Formation replacing the old one.

Humans usually cannot eliminate an old habit, they can only replace it with a new, hopefully, healthy one which will inevitably involve the wrong feeling of cognitive-emotive dissonance. Moreover, to replace a habit they need to practice the new habit more often than the old one and initially each time it will feel wrong until they practice long enough for it to feel right. This is exactly what any successful emotional change involves, but in many therapeutic approaches, patients are expected to get through it without being properly coached. Participants often say "I know it in my head but I don't feel it in my heart," indicating that they achieved intellectual insight but do not understand what it takes to gain emotional insight and eventually to change their habits. 


\section{Target Populations}

Maultsby put a significant emphasis on proper differential diagnosis because RBT, providing emotional and behavioral re-learning, can effectively only be applied to learned problems. However, it is still applicable in people with primarily nonlearned mental disorders like bipolar disorder and schizophrenia as soon as they are stable enough to address their secondarily learned problems. For people who have delusions and hallucinations, the self-help qualities of RBT are appealing and can be used to challenge their delusions as well as their beliefs about the content of hallucinations (e.g. that they are all-powerful and cannot be resisted).

The authors agree with Ellis that RBT, similarly to REBT, is "most effective when used with bright individuals who are motivated to change, who are willing to embrace REBT's humanistic and life-enhancing philosophy, and who make the ongoing effort required for solid and lasting change" (Ellis and Joffe-Ellis 2011). Ellis, however, further elaborated that it is not usually effective with people "who exhibit resistance, laziness, low frustration tolerance, and the desire for change to be easy and effortless (i.e., magical thinking); and who have narcissistic, rigidly dogmatic, and hypomanic tendencies" (Ellis and Joffe-Ellis 2011). Maultsby, on the other hand, would consider such people as those in the greatest need of RBT and who would benefit from it the most. He encouraged everyone to refer to him their "resistant patients" (he considered this term to be a misnomer resulting from lack of understanding of the emotional re-learning process). He also conducted many workshops for therapists on practical ways of dealing with resistant and difficult patients (e.g., NACBT Conference, San Francisco, June 2004).

One of Maultsby's greatest goals was reaching diverse recipients, with different socio-economic statuses, and dealing with a wide array of learned emotional problems, among populations including children and adolescents, married couples, the elderly, and prisoners (Gore and Maultsby 2008; Maultsby Jr 1977, 1986, 1988; Maultsby and Carpenter 1978; Maultsby et al. 1974; Patton 1992). Maultsby emphasized the "culture-free" aspects of RBT to make it acceptable to most people regardless of their background or education, including illiterate participants (Maultsby Jr 1982b). He developed the self-counseling features of RBT to address the needs of underprivileged populations who usually did not have access to mental health services, particularly those delivered in traditional, paternalistic ways (Maultsby Jr 1982a).

RBT, especially when delivered in a group setting, is a very inexpensive form of intervention. Maultsby promoted the idea of classroom education of emotional competence based on RBT for its preventive qualities (Knipping et al. 1976; Maultsby et al. 1974; Stehno 1986). He developed one of the very early applications of cognitive-behavior therapies to substance abuse and formulated it in a self-help format to reach the widest population (Gore and Maultsby 2008; Maultsby Jr 1978). The selfhelp qualities of RBT also appeal to medically ill participants who do not have primarily mental health issues (Maultsby Jr 2013; Simonton et al. 1992; Wirga 2012; Zielazny et al. 2016). Since 2004, the program combining RBT and Simontonian Therapy is offered at the MemorialCare Todd Cancer Institute (TCI) in Long Beach, 
California as the Beat the Odds-A Comprehensive Cancer Survivorship Program. At TCI, a Virtual Reality RBT/Beat the Odds platform for cancer patients is being developed to facilitate access to psychosocial interventions, to improve adherence with cognitive-behavioral homework, and to enhance participants' well-being during treatments (Porabiak et al. 2018)

The application of Rational Self-Counseling to non-clinical populations (people who do not have a diagnosable mental illness) was used to help them resolve daily stresses of life, deal with greater challenges like earlier mentioned life-threatening chronic illnesses, divorces, losses, career problems, etc. An egalitarian at heart, Maultsby welcomed the initiatives by lay-people to learn, apply, and even teach RBT skills. In 1970, former participants of Maultsby's RBT groups in Madison Wisconsin incorporated the Associated Rational Thinkers later renamed the Association for Rational Thinkers (ART) that was issuing a newsletter ART in Daily Living and its own journal Perspectives in Emotional Self-Help. By 1975 it had over 1200 members in the USA, Australia, Germany, India, Israel, UK, and even Tasmania becoming International Association for Clear Thinking (I'ACT) (Maultsby Jr 1975). Maultsby considered its local chapters as "excellent examples of how community groups, by teaching classes in Rational Self-Counseling, can give their communities effective, economical programs in mass mental-health improvement" (Maultsby Jr 1984, p. 11). I'ACT has continued for almost 40 years under the leadership of its CEO Shirley Bender-Gehrt. Also, informal groups sprang up like OIL Klub in Bydgoszcz, Poland (OIL is the acronym for Fallible Human Being-FHB in Polish) that was initiated in 2014 by Wojciech Falkowski around the local Adult Children of Alcoholics support group.

The obesity epidemic in the USA and the challenges in implementing effective lifestyle modification programs particularly in the medically ill populations was a spur of combining RBT with the modern behavioral change interventions. RBT is particularly compatible with the Theory of Planned Behavior, Reasoned Action Approach (Fishbein and Ajzen 2010). The interventions are applied in the Boost the Odds-From Cancer Survivor to Life Thriver program at the MemorialCare Todd Cancer Institute in Long Beach, California, and described in more detail in the second volume of the upcoming new edition of the "ABC of Your Emotions" (Maultsby Jr et al. 2020).

\section{Profound Philosophical Change and Hopeful Non-attachment}

A thorough personal integration of the radical stance of RBT's ABCD of emotions (that "I create, maintain and eliminate all my emotional feelings with learned thoughts, beliefs and attitudes") by itself facilitates a deep change in people that results in exercising what Maultsby called "our birthright to be happy." People in extreme situations may discover the validity of ABCD themselves, like psychiatrist and Holocaust survivor Viktor E. Frankl, that "... the last of human freedoms- to choose one's attitude in any given set of circumstances, to choose one's own way" (Frankl 2006, p. 66). 
Maultsby also observed that for whatever situation we are in and surviving, we are actually "accepting it", however miserably. According to ABCD, whatever we accept miserably, we can learn to accept less miserably, neutrally, or even happily. This combined with what RBT inherited from Albert Ellis' REBT and also adopted from Marsha Linehan's Dialectical Behavior Therapy (DBT), namely radical and unconditional acceptance of self (RUSA), others (RUOA) and life conditions (RULA), in addition to healthy shoulds (freedom from moralistic, idealistic, absolutistic shoulds, musts, have tos and ought tos), leads to a profound philosophical change which is further deepened by the RBT concept of non-attachment to outcome. Non-attachment to outcome is a unique form of radical unconditional future acceptance (RUFA) and reflects the cultivation of an attitude and skills that I will allow me to calmly accept, or will do my best to be okay, no matter what challenges may come my way, in the future. It also recognizes that adversities in life are inevitable, but the emotional suffering is optional. It counters many common (what Ellis would call "musturbatory" and "demanding") unhealthy beliefs about the future.

In 1985, Maultsby became interested in psychosocial oncology interventions and started working with Dr. O. Carl Simonton, MD, a radiation oncologist who, since 1971, was exploring the ways of addressing the psychological needs of cancer patients and their loved ones. RBT was adopted as a main cognitive-behavioral framework for what Simonton had been trying to accomplish, and he credited it for being the most important change in his program since the very beginning of his work. RSA was simplified to what was most effective for this population, Belief Work (Simonton et al. 1992, pp. 67-73). From the Simontonian Therapy perspective, RBT adopted the philosophical stance of balancing caring with non-attachment to an outcome, which is a practice that counters habitual "attachment" to an outcome. The latter is the implied but unrealistic imperative that what we want has to happen or be a certain way (e.g., "I have to keep getting better and better every day," "Chemo should have no side-effects," "I should be better by now," or "I have to exercise more, lose weight, have more energy, etc.") or constant questioning oneself ("how long will I live?," "is this chemo working?," "do these aches mean metastases?," etc.). This attachment to outcome is believed to cause chronic emotional tension and is a source of distress for patients and caregivers. It is conceptualized that eventually this tension or fear of disappointments (or actual series of disappointments) leads to what is commonly called burnout and an assumption of an opposite attitude of "detachment." Detachment, in turn, may lead to not-caring, "giving up," disengagement from treatment and life activities, and in advanced cases to sarcasm, cynicism, or nihilism (some psychodynamically oriented therapists could see it as reaction formation).

As an intervention, an alternative approach is promoted of "balancing caring with non-attachment," that is characterized by being actively engaged in succeeding but instead of focusing on the future, focusing on being involved and committed to what can be done in the present moment to increase the likelihood of attaining desired outcomes. This non-attachment also involves a deep awareness that this outcome may not necessarily be reached, understanding that we may have an influence on the course of our lives, but ultimately we do not control them. In the case of cancer patients, it may be not asking oneself "how long will I live?", but focusing on 
answering the question "how will I live?" that changes the emphasis to what I can do today to improve the quality of my life and the likelihood of desired outcomes. In our clinical practice, we noticed a significant decrease in anxiety in participants who apply this approach.

However, similarly to advising mindfulness or nonjudgmental attitude, we recommend that people remain "not attached to becoming non-attached" and radically accept their innate tendency to continuously getting attached. It seems that just the awareness of the process of attachment leads to the immediate deconstruction of it as soon as the person becomes aware of it, and this leads to a significant decrease in anxiety. Therefore, the acceptance in non-attachment is a different process than in REBT (cognitive restructuring) and Acceptance and Commitment Therapy-ACT (detached attitude) (Wild et al. 2017). In RBT, acceptance in non-attachment combines the development of healthier beliefs with the adoption of an attitude focused on the process in the present moment rather than on the outcome.

Some people exposed to the idea of non-attachment mistakenly believe that it may decrease motivation. Clinical practice indicates that the opposite is happening. As Dan Harris noted, "nonattachment to results + self compassion $=$ a supple relentlessness that is hard to match. Push hard, play to win, but don't assume the fetal position if things don't go your way" (Harris 2014). As a matter of fact, non-attachment is the important motivational technique of paradoxical agenda setting and sitting with open hands in Burns' TEAM-CBT approach (he in turn credits Dryden for inspiring it; (Burns 2005).

A related concept that RBT adopted from Simontonian Therapy is the instillation and promotion of "healthy hopefulness" that incorporates non-attachment. Simonton expanded on Webster's definition of hope that "hope is a belief that what I desire, I can achieve even when the probabilities are small." The definition is non-attached but engaged. "I can achieve" is used, in contrast to "I will achieve," where the latter reflects positive (but not necessarily healthy) thinking or "I have to achieve" that reflects the attachment to an outcome. To tailor the treatment to the cancer context, we consider that cancer patients may often feel hopeless when important life goals, established prior to the illness, become or seem unattainable because of their medical diagnosis. Therefore, the process of goal identification will include discussion of the ways in which cancer has affected their goals, and using a values assessment to identify new or modified meaningful goals and strategies to achieve them with non-attachment. It is also recognized, that people may develop such a non-attached attitude that will allow them to find equanimity without the need for hope (Wirga 2012).

\section{Spiritual and Philosophical Counseling}

The authors have significant experience in working with patients with life-threatening illnesses, particularly cancer, which may cause patients and their loved ones to frequently question their own religious, spiritual, existential or deeply-held philosophical beliefs and can lead to an existential crisis or prolonged distress and profound suffering. People experiencing this type of crisis often describe this suffering 
as much worse than any physical or emotional pain they have ever experienced or imagine experiencing. For therapists, it may constitute a significant challenge not just because of the intensity of this suffering but also the need to offer help to participants who have very different spiritual or philosophical beliefs than practitioners. What makes things more difficult here is that there has been no agreed upon way to assess if these beliefs are right or wrong. Any attempts at challenging them may be considered deeply offensive or blasphemous to the participant.

To address this need, one of the authors (Wirga) formulated Nondenominational, Cognitive-Behavioral Spiritual and/or Existential Counseling (Wirga 2010), based on the work of Maultsby and Simonton. It is the application of the simplified version of RSA limited only to sections B and HB (so called Belief Work), which does not use the first rule (based on facts) of the 5RHT since we agree that in this area we will not be discussing the factual aspects of the religious, spiritual, existential or philosophical beliefs. Such healthy beliefs would obey at least 3 of the remaining 4 RHT. This approach can be used individually. However, it particularly lends itself for group work where participants, in a nonjudgmental, supportive environment, may be exposed to diverse ways of looking at the health value of their foundational beliefs and have opportunities to get group input in formulating their new, healthy ones. This teaches them practical skills to resolve not only such existential crises or suffering in the future but any other emotional crisis as well.

\section{Goals of Therapy}

In RBT the emotional and behavioral goals of therapy are formulated with the participant and are revisited regularly. If goals are not achieved, therapists and their participants explore why not and what can be done about it. However, the ultimate goal of achieving the above mentioned philosophical transformation was, as Maultsby used to say, to "help people help themselves to happiness."

Ellis and Dryden considered changing unhealthy emotions to either healthy positive emotions or healthy negative emotions that include healthy anger, jealousy, envy, concern, sadness, remorse, disappointment, and sorrow as a therapy goal. Burns, on the other hand, considered this a "non-problem, such as healthy sadness or grief, where no therapeutic techniques other than empathic listening are required" (Burns 2005, p. 384).

While Maultsby did not regard these negative emotions as pathological, he recognized that they are learned and therefore can be re-learned to personal satisfaction. He was not spared significant personal tragedies (i.e., the loss of both of his sons) but always emphasized that in the face of any situation, people have three emotional choices: negative, neutral or positive. He often encouraged that the initially the goal of therapy was to be "less miserable," then to be "even less miserable" because this step-wise approach was creating less cognitive-emotive dissonance and seemed more achievable and acceptable as a goal. Eventually, the therapy was focused on having "neutral" emotional feelings to replace the intense negative ones. He observed that while it may be neurophysiologically possible, people rarely are interested in working to be happy about things they feel 
currently miserable (with the exception of procrastination and irrational fears of personally desirable actions) (Maultsby Jr 1984).

Still, Maultsby encouraged participants and trainees to continue to apply Rational Self-Counseling to not only resolve their misery but to fulfill their "birthright to be happy." The attitude of non-attachment focused on the process of achieving joy in the present moment is consistent with Thich Nhat Hanh's statement that "there is no way to happiness-happiness is the way." In recent years, inspired by Simonton, the authors found it easier for participants to focus on joy rather than happiness as a goal. Semantically, the term joy is more precise than common day use of happiness and causes less confusion or resistance. Also, it gives us immediate feedback as a "feeling of joy" while people do not have a clear idea of how happiness may feel in a given moment.

Maultsby and Simonton recognized joy as a natural state of mind of a healthy brain once it is free from unhealthy conditioning. The distinction between joy and pleasure is critical. Joy, while pleasant, is not pleasure. Joy is in harmony with our biology, values, relationships, and spirituality or philosophy and, therefore, it does not cause a headache, feelings of guilt or shame the next day as many pleasant activities do. Recalling joy with others brings us joy too, while often we would like to forget or erase some of the pleasant escapades. This distinction is similar to the difference of eudaimonia and hedonia in ancient Greek philosophy and may actually have different effects on our well-being and distinct gene regulatory programs (Fredrickson et al. 2013; Huta and Waterman 2014). Many people end up chasing pleasures, which is never satisfying and often is in conflict with our nature, values, and ecology. Joy, on the other hand, is ultimately satisfying: bringing more joy to everyday life leads to happiness.

\section{Preventive Qualities and Professional Burnout}

Early on, Maultsby, similarly to Ellis, recognized the value of learning "emotional competence" that self-counseling properties of RBT could provide to young people with the intent to prevent bigger emotional and behavioral problems in the future (Knipping et al. 1976; Maultsby et al. 1974). Furthermore, RBT supports a healthy lifestyle and is an excellent practical extension of the Reasoned Action Approach for lifestyle modification (Fishbein and Ajzen 2010).

Training in RBT includes the practice of applying all of its tools to oneself, which prevents professional burnout. A thorough integration of ABCD's, 5RHT, and healthy semantics, and, most prominently, the attitude of non-attachment and radical unconditional acceptance in both personal and professional life, results in taking reasonability for one's mood states. With this comes the recognition that the work does not "burn out" the person. RBT clinicians take responsibility for not only creating their own emotional distress but also for participating in the workplace that may be in conflict with their ideals, goals, and values. The application of RBT in burnout prevention and treatment is very important but goes beyond the scope of this article. 


\section{Conclusion}

The authors recognize that the lack of recent studies of the application of RBT, particularly compared to other CBTs, is its most significant disadvantage. Most of the RBT adherents are clinicians, not academics. We even joke that we like applying it so much because it is so effective and that we have no desire to do anything else at work. We hope, however, that the new cadre of young, academically inclined colleagues will fill that important gap in research. Also, we do not think that RBT answers all the questions and agree with Burns who said that "I'm convinced that many of our most cherished theories about the causes of emotional distress will eventually be proven false, and that our best treatment techniques will be eclipsed by vastly more effective methods in the future" (Burns 2005). Simonton used to say, "it is not about who is wrong and who is right; we all are wrong; all that matters is to what degree." Nevertheless, the authors believe that we do not need to wait for future developments. Right now, any therapist may significantly improve the outcomes of their interventions regardless of which CBT school they profess by adding strong emphasis on the radical version of ABCD model of emotions; Five Rules for Healthy Thinking and RSA; educating the patients about cognitive-emotive dissonance as an inevitable part of effective change; and using imagery to rehearse new cognitive, emotional and behavioral responses to the old situations. The value of these techniques is that not only are they transcultural and transdiagnostic, they can address spiritual and philosophical/existential beliefs but also, as Simonton used to say, "are relatively easy to teach and easy to learn." Integration seems to be the next wave of cognitive behavior therapies (David and Cristea 2018) and we believe that the inclusion of RBT in the process would benefit the field and ultimately the therapy participants.

\section{Compliance with Ethical Standards}

Conflict of interest The authors declare that they have no conflict of interest.

Open Access This article is licensed under a Creative Commons Attribution 4.0 International License, which permits use, sharing, adaptation, distribution and reproduction in any medium or format, as long as you give appropriate credit to the original author(s) and the source, provide a link to the Creative Commons licence, and indicate if changes were made. The images or other third party material in this article are included in the article's Creative Commons licence, unless indicated otherwise in a credit line to the material. If material is not included in the article's Creative Commons licence and your intended use is not permitted by statutory regulation or exceeds the permitted use, you will need to obtain permission directly from the copyright holder. To view a copy of this licence, visit http://creativecommons.org/licen ses/by/4.0/. 


\section{Appendix 1: The ABCD Model of Emotions}
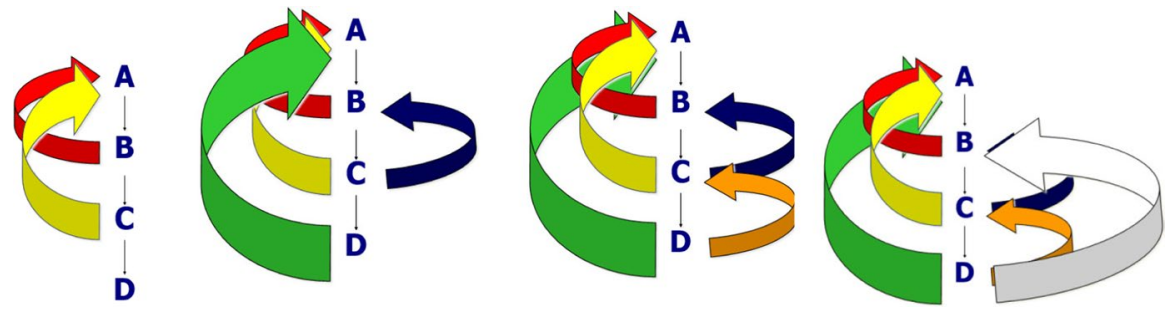

Each element of the ABCD model of emotions can become a new A, or affect other elements

\section{Appendix 2: Standard Rational Analysis Form}

A. ACTIVATING EVENT (What happened?)

Briefly describe the event (facts) that you want to work on using words that actually reflect your memory of the event

\section{B. YOUR BELIEFS (What did you think?)}

Internal dialogue, your sincere thoughts and beliefs about A. List each thought or belief that you had about the activating event A. Try not to censor your thoughts. Use as much space as you need (you can also write on the other side of the paper or use additional sheets of paper)

B1

B2

B3

\section{EMOTIONAL FEELINGS (What emotions did you feel?)}

Simple statements of how you felt during the event. Rate the level of emotional discomfort on a scale of one to ten, with one meaning calmness and ten being the most intense painful emotion that you have ever experienced

\section{ACTIONS (what did you do?)}

Describe what you did during the event or immediately after

\section{HA. CAMERA TEST OF PERCEPTIONS (What}

factually happened?)

Check everything that you have written in Section A to see if these are facts. The best way to do this is to ask yourself to describe exactly what would have been captured by a video camera recording the event. What would not be recorded by a video camera does not pass the camera test of perceptions and most likely belongs to section $\mathrm{B}$ (because it is a belief) or C (because is an emotion)

\section{HB. HEALTHY DEBATE WITH B (What would be healthier to think?)}

To each thought or belief in Section B, apply the Five Questions for Healthy Thinking (5QHT). If you answer "yes" to at least three of the 5QHT, you can call the belief healthy and move on. If a belief answers "yes" to only two or less of the $5 \mathrm{QHT}$, this means that the belief is unhealthy Across from this unhealthy belief, in the section $\mathrm{HB}$ below, write an alternative, healthy belief that is incompatible with the one you are replacing and that will obey at least three of five RHT. Proceed this way for each belief you listed in section B

HB1

HB2

HB3

HC. EMOTIVE GOALS (What would you like to feel?) What healthy feelings you would like to experience in a similar future situation?

HD. BEHAVIORAL GOALS (What would you like to do?)

How would you rather behave in similar future situations? 
Five Questions for Healthy Thinking

1. Is this thought based on obvious facts (objective - A healthy belief obeys at least three of the five reality)? rules.

2. Does this thought best protect my life and

- What is healthy thinking for me does not have to health? be healthy for another person, so what is healthy for the therapist does not have to be healthy for the participant.

3. Does this thought best help me to achieve my short and long-term goals?

- What is healthy for me today does not have to be healthy for me at other times.

4. Does this thought best help me to prevent or

- All the rules are equally important. handle the most unwanted conflicts with others?

5. Does this thought best help me feel the way I want to feel, without abusing any substances?

- Some rules may not be applicable in certain situations (e.g., rule number one doesn't apply to religious, spiritual, philosophical or existential beliefs).

\section{Appendix 3: The acquisition of an emotional habit with the example of fear of flying}

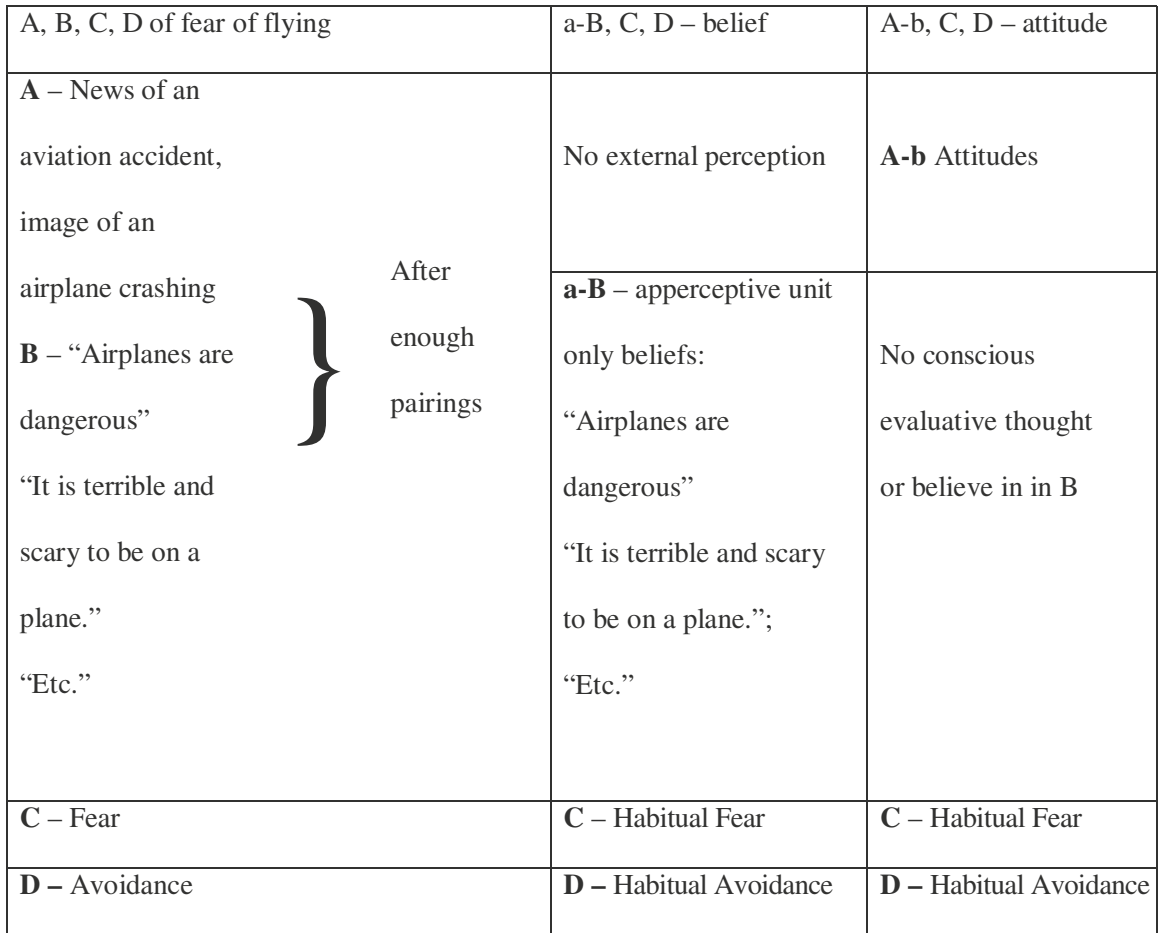

With enough unwitting mental practice of a particular ABCD, a new habitual emotion (an attitude) is formed 


\section{Appendix 4: Emotional Learning and Re-Learning in Psychosomatic Learning Theory}

The process of changing emotional habits in Emotional Re-Learning involves the stage of CognitiveEmotive Dissonance - as soon as the person is engaging in a new thinking or behaving on old situations, it immediately feels wrong, weird, awkward, unnatural and reversing to the old behavior feels "right" even though it may be dangerous and objectively wrong. That is the stage when many uninformed people quit their change efforts or assigned practice

\begin{tabular}{ll}
\hline Emotional Learning & Emotional Re-Learning \\
1) Intellectual Insight & 1) Intellectual Insight \\
2) Practice & 2) Practice \\
A. Mental (self-instruction, mental images) & A. Mental (self-instruction, mental images) \\
B. In real life & B. In real life \\
& 3) COGNITIVE-EMOTIVE DISSONANCE \\
3) Emotional Insight & 4) Emotional insight \\
4) New Habit Formation & 5) New Habit Formation replacing the old one
\end{tabular}

\section{References}

Al-Mosaiwi, M., \& Johnstone, T. (2018). In an absolute state: Elevated use of absolutist words is a marker specific to anxiety, depression, and suicidal ideation. Clinical Psychological Science. https:// doi.org/10.1177/2167702617747074.

Burns, D. D. (1981). Feeling good. The new mood therapy. Signet, New American Library. https://doi. org/10.1016/0005-7967(82)90075-4.

Burns, D. D. (2005). In S. L. Burns (Ed.), Tools, not schools, of therapy (Version 5). Los Altos Hills: Author.

Burns, D. D. (2017). High-speed treatment of depression and anxiety disorders. In A Four-Day TEAM$C B T$ advanced intensive. Burlingame, CA: Institute for the Advancement of Human Behavior.

David, D., \& Cristea, I. (2018). The new great psychotherapy debate: Scientific integrated psychotherapy vs. plurality. Why cognitive-behavior therapy is the gold standard in psychotherapy and a platform for scientific integrated psychotherapy. Journal of Evidence-Based Psychotherapies, 18(2), 1-17.

Dryden, W. (2012a). The "ABCs" of REBT I: A preliminary study of errors and confusions in counselling and psychotherapy textbooks. Journal of Rational - Emotive and Cognitive - Behavior Therapy, 30(3), 133-172. https://doi.org/10.1007/s10942-011-0137-1.

Dryden, W. (2012b). The "ABCs" of REBT III: A study of errors and confusions made by Ellis and Joffe Ellis (2011). Journal of Rational - Emotive and Cognitive - Behavior Therapy, 30(3), 188-201. https ://doi.org/10.1007/s10942-011-0140-6.

Ellis, A. (1979). A note on the treatment of agoraphobics with cognitive modification versus prolonged exposure in vivo. Behaviour Research and Therapy, 17(2), 162-164. https://doi.org/10.1016/00057967(79)90027-5.

Ellis, A. (1987). A sadly neglected cognitive element in depression. Cognitive Therapy and Research, 11(1), 121-145. https://doi.org/10.1007/BF01183137.

Ellis, A., \& Joffe-Ellis, D. (2011). Rational emotive behavior therapy. American Psychological Association. Retrieved from https://www.amazon.com/Rational-Emotive-Behavior-Theories-Psych otherapy-ebook/dp/B006C3QA3U/ref=tmm_kin_swatch_0?_encoding=UTF8\&qid=1504550297 $\& \mathrm{sr}=1-6$

Fishbein, M., \& Ajzen, I. (2010). Predicting and changing behavior: The Reasoned Action Approach. Psychology. https://doi.org/10.4324/9780203937082.

Frankl, V. E. (2006). Man's search for meaning. Boston: Beacon Press. 
Fredrickson, B. L., Grewen, K. M., Coffey, K. A., Algoe, S. B., Firestine, A. M., Arevalo, J. M. G., et al. (2013). A functional genomic perspective on human well-being. Proceedings of the National Academy of Sciences of the United States of America, 110(33), 13684-13689. https://doi.org/10.1073/ pnas. 1305419110.

Gore, T. A., \& Maultsby, M. C. (2008). The rational alcoholic relapse-prevention treatment method: A new self-help alcoholism treatment method. Alcoholism Treatment Quarterly, 2(3-4), 243-247. https://doi.org/10.1080/J020V02N03_15.

Harris, D. (2014). 10\% happier: how I tamed the voice in my head, reduced stress without losing my edge, and found self-help that actually works : A true story. It Books.

Huta, V., \& Waterman, A. S. (2014). Eudaimonia and its distinction from Hedonia: Developing a classification and terminology for understanding conceptual and operational definitions. Journal of Happiness Studies, 15(6), 1425-1456. https://doi.org/10.1007/s10902-013-9485-0.

Knipping, P. A., Maultsby, M. C., \& Thompson, R. (1976). The technology for using the classroom as an emotional health center. The Journal of School Health, 46(5), 278-281. Retrieved from http://www. ncbi.nlm.nih.gov/pubmed/58137

LeDoux, J. E. (1995). In search of an emotional system in the brain: Leaping from fear to emotion and consciousness. In M. S. Gazzaniga (Ed.), The cognitive neurosciences (pp. 1049-1061). Cambridge, Massachusetts: MIT Press.

LeDoux, J. E. (2002). Synaptic self: How our brains become who we are. New York: Viking.

LeDoux, J. E., \& Brown, R. (2017). A higher-order theory of emotional consciousness. Proceedings of the National Academy of Sciences, 114(10), E2016-E2025. https://doi.org/10.1073/pnas.16193 16114.

LeDoux, J. E., \& Hofmann, S. G. (2018). The subjective experience of emotion: A fearful view. Current Opinion in Behavioral Sciences, 19, 67-72. https://doi.org/10.1016/j.cobeha.2017.09.011.

MacLaren, C., Doyle, K. A., \& DiGiuseppe, R. (2016). Rational emotive behavior therapy (REBT): Theory and practice. In H. E. A. Tinsley, S. H. Lease, \& N. S. Griffin Wiersma (Eds.), Contemporary theory and practice in counseling and psychotherapy (Vol. 1, pp. 233-263). SAGE Publishing. Retrieved from https://in.sagepub.com/sites/default/files/upm-binaries/68308_Tinsley_Chapter_9. pdf

Maultsby, M. C., Jr. (1971a). Rational emotive imagery. Rational Living, 6(1), 24-27. Retrieved from http://search.ebscohost.com/login.aspx?direct=true\&db=psyh\&AN=1972-10965-001\&site=ehost -live

Maultsby, M. C., Jr. (1971b). Systematic, written homework in psychotherapy. Psychotherapy: Theory, Research \& Practice, 8(3), 195-198. https://doi.org/10.1037/h0086657.

Maultsby, M. C., Jr. (1975). Help yourself to happiness trough rational self-counseling. New York, NY: Institute for Rational Living.

Maultsby, M. C., Jr. (1977). Helping prisoners help themselves, rationally. In Institute of contemporary corrections and the behavioral sciences, 12th annual interagency workshop-proceedings (pp. 5-12). Huntsville, TX: Sam Houston State University Criminal Justice Ctr. Retrieved from https:// www.ncjrs.gov/App/Publications/abstract.aspx?ID=50666

Maultsby, M. C., Jr. (1978). A million dollars for your hangover (the illustrated guide for the new self-help alcoholic treatment method). Rational Self-Help Books. Retrieved from https://www.amazon.com/ Hangover-Illustrated-Self-Help-Alcoholic-Treatment/dp/B000OS08UU/ref=sr_1_17?s=books $\&$ ie $=$ UTF8\&qid $=1505013476 \&$ sr $=1-17 \&$ keywords $=$ Maultsby

Maultsby, M. C., Jr. (1982a). A historical view of blacks' distrust of psychiatry. In S. M. Turner \& R. T. Jones (Eds.), Behavior modification in black populations, psychosocial issues and empirical findings (pp. 39-55). New York, NY: Plenum Press. https://doi.org/10.1007/978-1-4684-4100-0_3.

Maultsby, M. C., Jr. (1982b). Guidelines for Illiterate Patients in RBT. In S. M. Turner \& R. T. Jones (Eds.), Behavior Modification in Black Populations, Psychosocial Issues and Empirical Findings (pp. 214-215). New York, NY: Plenum Press. Retrieved from https://play.google.com/books/reade $\mathrm{r} ? \mathrm{id}=\mathrm{HBq} 4 \mathrm{BgAAQBAJ} \&$ printsec $=$ frontcover $\& \mathrm{pg}=\mathrm{GBS} . \mathrm{PT} 218$

Maultsby, M. C., Jr. (1984). Rational behavior therapy. Englewood Cliffs, NJ: Prentice Hall.

Maultsby, M. C., Jr. (1986). Teaching rational self-counseling to middle graders. The School Counselor: American School Counselor Association. https://doi.org/10.2307/23900676.

Maultsby, M. C., Jr. (1988). A needed change in traditional marriage counseling. Alabama ACD Journal, $14(2), 5-12$.

Maultsby, M. C., Jr. (2013). In M. Wirga, A. Hottowy, \& E. Wojtyna (Eds.), Racjonalna Terapia Zachowania: podręcznik terapii poznawczo-behawioralnej (3rd ed.). Żnin: WDK Wulkan. 
Maultsby, M. C., \& Carpenter, L. (1978). Emotional self defense for the elderly. Journal of Psychedelic Drugs, 10(2), 157-160. https://doi.org/10.1080/02791072.1978.10472081.

Maultsby, M. C., Knipping, P., \& Carpenter, L. (1974). Teaching self-help in the classroom with rational self-counseling. Journal of School Health, 44(8), 445-448. https://doi. org/10.1111/j.1746-1561.1974.tb01945.x.

Maultsby, M. C., Jr., \& Winkler, P. (1972). Directed rational self-counseling (a new approach to mass mental health). ANA Clinical Sessions, 234-237. Retrieved from http://www.ncbi.nlm.nih.gov/ pubmed/4127013

Maultsby, M. C., Jr., Wirga, M., \& DeBernardi, M. (2020). ABC of Your Emotions - prepublication manuscript.

Ortner, C. N. M., Marie, M. S., \& Corno, D. (2016). Cognitive costs of reappraisal depend on both emotional stimulus intensity and individual differences in habitual reappraisal. PLOS ONE, 11(12), 1-18. https://doi.org/10.1371/journal.pone.0167253.

Patton, P. L. (1992, January). Rational behavior training: A seven lesson sequence for teaching rational behavior skills to students with social and emotional disabilities. Rational Self-Help Aids/I'ACT, 3939 Spencer St., Appleton, WI 54914. Retrieved from https://eric.ed.gov/?id=ED350807

Pulvermüller, F. (2013). How neurons make meaning: Brain mechanisms for embodied and abstractsymbolic semantics. Trends in Cognitive Sciences, 17, 458-470. https://doi.org/10.1016/j. tics.2013.06.004.

Rahnev, D., Lau, H., \& de Lange, F. P. (2011). Prior expectation modulates the interaction between sensory and prefrontal regions in the human brain. The Journal of Neuroscience: The Official Journal of the Society for Neuroscience, 31(29), 10741-10748. https://doi.org/10.1523/JNEUR OSCI.1478-11.2011.

Rahnev, D., Nee, D. E., Riddle, J., Larson, A. S., \& D’Esposito, M. (2016). Causal evidence for frontal cortex organization for perceptual decision making. Proceedings of the National Academy of Sciences. https://doi.org/10.1073/pnas.1522551113.

Schachter, S., \& Singer, J. E. (1962). Cognitive, social, and physiological determinants of emotional state. Psychological Review, 69, 379-399. Retrieved from http://www.ncbi.nlm.nih.gov/pubmed/14497 895

Simonton, O. C., Henson, R. M., \& Hampton, B. (1992). The healing journey. New York, NY: Bantam Books.

Stehno, J. (1986). Rational behavior therapy in experiential learning. Bradford Papers Annual, 1, $25-27$.

Tomasello, R., Garagnani, M., Wennekers, T., \& Pulvermüller, F. (2017). Brain connections of words, perceptions and actions: A neurobiological model of spatio-temporal semantic activation in the human cortex. Neuropsychologia, 98, 111-129. https://doi.org/10.1016/J.NEUROPSYCHOLOGI A.2016.07.004.

Wirga, M. (2010). Nondenominational, cognitive-behavioral spiritual and/or existential counseling. In APOS 7th annual conference, 19 February 2010: SYMPOSIUM: Spirituality and cancer: how it helps and how to effectively help clients use it to cope. New Orleans. Retrieved from http://apos. conference-services.net/reports/template/onetextabstract.xml?xsl=template/onetextabstract .$x s 1 \&$ conferenceID $=1865 \&$ abstractID $=352814$

Wirga, M. (2012). Suffering: Its anatomy, physiology and mystique demystified from the Nondual Medicine Perspective. In J. Binnebesel, Z. Formella, P. Krakowiak, \& Z. Domzal (Eds.), Experiencing a suffering (Vol. 1, pp. 121-147). Rome: LAS_Libreria Ateneo Salesiano.

Wirga, M., \& DeBernardi, M. (2002). The ABCs of cognition, emotion, and action. Archives of Psychiatry and Psychotherapy, 4(1), 5-16.

Zielazny, P., Zielińska, P., de Walden-Gałuszko, K., Kuziemski, K., \& Bętkowska-Korpała, B. (2016). Psychooncology in Poland. Psychiatria Polska, 50(5), 1065-1073. https://doi.org/10.12740/ PP/60906.

Publisher's Note Springer Nature remains neutral with regard to jurisdictional claims in published maps and institutional affiliations. 